\title{
Ruptures and repairs of group therapy alliance. An untold story in psychotherapy research
}

\author{
Gianluca Lo Coco, ${ }^{1}$ Giorgio A. Tasca, ${ }^{2}$ Paul L. Hewitt, ${ }^{3}$ Samuel F. Mikail, ${ }^{4}$ Dennis M. Kivlighan, Jr. ${ }^{5}$
}

${ }^{1}$ Department of Psychology, Educational Science and Human Movement, University of Palermo, Italy; ${ }^{2}$ School of Psychology, University of Ottawa, Canada; ${ }^{3}$ Department of Psychology, University of British Columbia, Canada; ${ }^{4}$ Private Practice, Canada; ${ }^{5}$ Department of Counseling, Higher Education and Special Education, University of Maryland, USA

\begin{abstract}
Although previous studies investigated the characteristics of therapeutic alliance in group treatments, there is still a dearth of research on group alliance ruptures and repairs. The model by Safran and Muran was originally developed to address therapeutic alliance in individual therapies, and the usefulness of this approach to group intervention needs to be demonstrated. Alliance ruptures are possible at member to therapist, member to member, member to group levels. Moreover, repairs of ruptures in group are quite complex, i.e., because other group members have to process the rupture even if not directly involved. The aim of the current study is to review the empirical research on group alliance, and to examine whether the rupture repair model can be a suitable framework for clinical understanding and research of the complexity of therapeutic alliance in group treatments. We provide clinical vignettes and commentary to illustrate theoretical and research aspects of therapeutic alliance rupture and repair in groups. Our colleague Jeremy Safran made a substantial contribution to research on therapeutic alliance, and the current paper illustrates the enduring legacy of this work and its potential application to the group therapy context.
\end{abstract}

Key words: Group therapy; Therapeutic alliance; Rupture and repair; Group process.

Correspondence: Gianluca Lo Coco, Department of Psychology, Educational Science and Human Movement, University of Palermo, Viale delle Scienze, Edificio 15, 90128 Palermo, Italy. Tel.: +39.091.23897725.

E-mail: gianluca.lococo@unipa.it

Citation: Lo Coco, G., Tasca, G. A., Hewitt, P., Mikail, S. F., \& Kivlighan, Jr., D. M. (2019). Ruptures and repairs of group therapy alliance. An untold story in psychotherapy research. Research in Psychotherapy: Psychopathology, Process and Outcome, 22(1), 58-70. doi: 10.4081/ripppo.2019.352

Contributions: GLC and GAT conceived of the article and wrote the manuscript; PH and SFM provided the clinical material and participated in the critical revision of the manuscript; DMK wrote the methodological section and had overall responsibility. All authors approved the final version of the manuscript.

Conflict of interest: the authors declare no potential conflict of interest.

Funding: none.

Received for publication: 30 November 2018.

Revision received: 13 February 2019.

Accepted for publication: 2 March 2019.

This work is licensed under a Creative Commons Attribution NonCommercial 4.0 License (CC BY-NC 4.0).

(C) Copyright G. Lo Coco et al., 2019

Licensee PAGEPress, Italy

Research in Psychotherapy:

Psychopathology, Process and Outcome 2019; 22:58-70

doi:10.4081/ripppo.2019.352

\section{Introduction}

The therapeutic alliance is one of the most examined factors leading to patients' improvement in psychotherapy (Crits-Christoph, Gibbons, \& Mukherjee, 2013; Norcross $\&$ Lambert, 2018). In the last thirty years, research has consistently confirmed a positive association between alliance and treatment outcome across several treatment conditions (Doran, 2016; Flückiger, Del Re, Wampold \& Horvath, 2018; Horvath \& Bedi, 2002). Researchers have demonstrated that the therapeutic alliance even measured early in therapy is a significant predictor of psychotherapy outcome, with meta-analytic effect sizes ranging from .22 to .28 (Flückiger et al., 2018; Horvath, Del Re, Flückiger, \& Symonds, 2011; Martin, Garske \& Davis, 2000). The most recent meta-analysis on therapeutic alliance extracted data from 295 independent studies (with more than 30000 patients) and found an alliance-outcome association of $r=.278$ (Flückiger et al., 2018), confirming that the alliance is an important ingredient in producing therapeutic change.

In its modern definition, the therapeutic (or working) alliance refers to the collaborative stance between patient and therapist (Doran, 2016). Bordin (1994) proposed the working alliance as a pan-theoretical aspect of therapeutic relationship, and defined its three components: emotional bond between patient and therapist, agreement on tasks of therapy, and agreement on goals of therapy. Bordin's definition of the alliance is the most widely adopted to date and led the proliferation of empirical research in the 
field. However, the way that standard tools measure the strength of the working alliance is still an issue. There is an array of different reliable instruments to measure alliance, each using somewhat different but overlapping concepts (Flückiger et al., 2018), with the "confident collaborative relationship" as the most common theme across measures (Hatcher \& Barends, 1996). Existing measures may also miss information about tension or disagreement which may emerge in the therapy process (Doran, Safran, Waizmann, Bolger \& Muran, 2012).

Research on the therapeutic alliance over the past decades has addressed two fundamental issues of the process and role of the alliance for patient outcomes. First, using time-lagged longitudinal modeling approaches, researchers have examined if, in fact, change in the alliance causes subsequent symptom change (Falkenstrom, Granström, \& Holmqvist, 2013) or if the reverse is true, that symptom change increases the alliance which would then render the alliance practically less important (Strunk et al., 2010). After reviewing the bulk of this research, Zilcha-Mano (2017) concluded that there is sufficient evidence to suggest that previous change in the alliance does lead to subsequent symptom improvement across the course of therapy. Second, researchers have examined the therapeutic alliance as a dynamic process that fluctuates over time, with variations within and between therapy sessions. Research showed that the development of the alliance across sessions of therapy does not follow a linear trend but reflects a more complex dynamic process (Rubel, Bar-Kalifa, Atzil-Slonim, Schmidt, \& Lutz, 2018; Zilcha-Mano, 2017). For example, Kivlighan and Shaughnessy (2000) found that the quadratic modeling of alliance development across sessions (i.e., a high, low, high pattern), was a better predictor of successful patient outcome than a linear model of alliance growth.

Consistent with this notion, Safran and Muran (2000) suggested that the therapeutic alliance is characterized by rupture-repair episodes during the course of treatment, and that these processes can have an impact on patient outcomes. The rupture-repair model represents one of the most important innovations in therapeutic alliance research and practice since early 1990s. This model provides a comprehensive and dynamic representation of the therapeutic alliance, especially of its complex management in the therapeutic process. The model revolves around the construct of rupture, which was defined as "strains in the alliance...consisting either of disagreements about the tasks or goals of therapy or of problems in the bond dimension" (Safran \& Muran, 2000, p.16). Safran and Muran identified two types of alliance ruptures: withdrawal and confrontation. Withdrawal ruptures refer to those instances when the client responds to difficulties, misunderstandings, or disagreements in the therapeutic relationship by moving away from the therapist, either by falling silent, offering minimal responses to questions, or denying an aspect of his or her experience.
By contrast, a confrontation rupture is characterized by the client moving against the therapist, expressing anger or dissatisfaction with the therapist or treatment (Eubanks-Carter, Muran, \& Safran, 2010). When the therapist identifies an alliance rupture, he/she can adopt some resolution strategies, such as renegotiating the tasks and goals or addressing interpersonal tensions in the therapeutic relationship (Safran, Muran \& Eubanks-Carter, 2011). When resolved, ruptures can positively influence the therapeutic relationship and can lead to subsequent improvement of alliance and symptom levels (Eubanks-Carter, Gorman, \& Muran, 2012).

Most studies of alliance ruptures and repairs adopted a naturalistic approach by examining the alliance via the use of self-report or observer-rating methods. Research using self-reported assessment of alliance identifies ruptures and repairs by the fluctuation of alliance scores from session to session. For example, one recent and well-conducted study on alliance rupture and repairs in primary care (Larsson, Falkenström, Andersson, \& Holmqvist, 2018) defined alliance ruptures as a downward shift in alliance ratings of one point or more from one therapy session to the next. A repair was defined as a return of the score to the pre-rupture level or higher within three sessions. Observer-rated methods allow researchers to identify types of ruptures that patient (and therapist) may be unaware of, identify alliance fluctuations within a therapy session, and therapist resolution strategies. Such observer rating measures include the Rupture Resolution Rating System (3RS; Eubanks, Muran, \& Safran, 2015) and the Collaborative Interactions Scale (Colli, Gentile, Condino, \& Lingiardi, 2017).

The most recent meta-analysis on the association between alliance rupture-repair and outcome examined 11 studies (with 1314 patients) and yielded an effect size of $\mathrm{r}=.29, \mathrm{~d}=.62$, indicating a moderate positive relation between rupture resolution and patient outcome (Eubanks, Muran, \& Safran, 2018). Moreover, there was no difference in effect sizes between studies that identified ruptures directly by observer rating and those that measured ruptures via fluctuations in self-reported alliance scores. The rupture-repair process may represent both a problem and an opportunity in clinical settings. As Eubanks and colleagues (2018) recently suggested, the "unresolved ruptures are associated with poor outcome, but repaired ruptures are associated with good outcome", indicating a need for more sophisticated and complex research methodologies for examining the dynamics of alliance during the course of therapy (Zilcha-Mano, 2017).

Although the rupture repair model has become one of the most prominent theoretical and empirical frameworks in alliance research, its adoption in group therapy research has been limited to date. Our colleague Jeremy Safran made a substantial contribution to research on therapeutic alliance, and the current paper illustrates the enduring legacy of this work and its potential application 
to the group therapy context. Our aim is to review the empirical research on group alliance, and to examine whether the rupture-repair model can be a suitable framework for clinical understanding and research of the complexity of therapeutic alliance in group treatments. To illustrate, we present several clinical case examples of alliance rupture and repair in group therapy, and we describe a methodology for alliance rupture and repair research in groups.

\section{The therapeutic alliance in group treatment}

In the last twenty years, a considerable body of research supported the importance of group alliance and its beneficial association with patient outcomes (Burlingame, Strauss, \& Joyce, 2013). However, research on therapeutic alliance in groups is more complex than those in individual treatments. Previous research suggested that one of the main challenges was to define what the alliance is in group therapy, and what is its place within group therapeutic relationships (Beck \& Lewis, 2000). Researchers have adopted conceptual models of various group structural components that include member to therapist, member to member, and member to group relationships (Burlingame, MacKenzie, \& Strauss, 2004). For example, in group treatments, patients consider the relationship they develop with other group members to be as beneficial as their relationship with the group therapist (Holmes \& Kivlighan, 2000). However, most previous studies on group alliance relied on the self-reported assessment of the alliance between the group member and the therapist, thus ignoring the importance of the alliance with the other group members or with the group as a whole (Kivlighan, Lo Coco, \& Gullo, 2015). By contrast, the construct of group cohesion was originally developed to describe the group-as-a-whole process and its quality (Burlingame, Fuhriman \& Johnson, 2002), and cohesion has remained the most investigated therapeutic element in the group literature (Burlingame, McClendon, \& Yang, 2018). It is worth noting that some recent studies adopted modified alliance measures to assess member to member alliance or member to group alliance (Jensen \& Burlingame, 2018; Johnson, Burlingame, Olsen, Davies, \& Gleave, 2005; Tasca \& Lampard, 2012). Several researchers argued whether cohesion and alliance should be considered as equivalent constructs in group therapy or represent different therapeutic aspects of group therapeutic relationships (Bakali, Baldwin, \& Lorentzen, 2009; Burlingame et al., 2002; Johnson et al., 2005). In group treatment, a challenging question remains: with whom is the alliance made? Is the alliance in group therapy fundamentally a collaborative relationship with the therapist, with other group members, with the group as a whole, or with all these elements?

A growing consensus is emerging among researchers and clinicians on the role of the three structural compo- nents that comprise the therapeutic relationship in groups (Burlingame et al., 2013; Johnson et al., 2005). In the group context, the individual patient is simultaneously engaged: with the other patients who share a common group experience, with the group therapist (or co-therapists), and with the group as an entity with its own culture, rules, and dynamics (Gullo et al., 2015; Marogna \& Caccamo, 2014; Yalom \& Leszcz, 2005). These three structural dimensions lead to different levels of interaction and functioning in groups (Tasca, Francis, \& Balfour, 2014). At an intraindividual level, patients and therapists bring their own dynamics (e.g., attachment representations) to the group context (Kirchmann et al., 2009; Lo Coco et al., 2016; Marmarosh, Markin \& Spiegel, 2013; Marmarosh \& Tasca, 2013; Tasca et al., 2006). At the interpersonal level (i.e., member to member or member to therapist relationships), the individual dynamics of each group patient shape interactions with other group members and defines the interpersonal context of the group (Tasca et al., 2014). Finally, patients and therapist experience the group as a whole, with its own climate and cohesion (Yalom \& Leszcz, 2005). Therefore, the therapeutic alliance in groups can be multi-layered based on the different levels of functioning of the group. For example, a patient can experience a positive bond with the therapist, but a negative or neutral bond with some other group members (Kivlighan, Lo Coco, Oieni, Gullo, Pazzagli, \& Mazzeschi, 2017). In contrast, a patient can experience a positive bonding with the group (i.e., the feeling of being understood and helped in the group), but a weak bond with the leader, whose interventions are perceived by the patient as not as important as they should be.

Given the different structural relationships in groups, several studies have compared the relative contributions of the relationship with the group leader, the group members and the group-as-a-whole to the prediction of group member outcome. For example, Marziali, Munroe-Blum, and McCleary (1997) found that the working alliance with the group leader and the relationships within the group were both significantly and independently related to member outcome; however, the working alliance with the leader accounted for a greater proportion of variance in patient outcome. In contrast, Crowe and Grenyer (2008) found that group members' working alliances with the group leader were not related to their outcome, but positive relationships with the group-as-a-whole did predict outcome. Owen, Antle, and Barbee (2013) also found that cohesion among the group members, but not the working alliance with the group leader significantly contributed to member outcome.

At this stage the literature is marked by inconsistencies because researchers used different measures to examine group therapeutic relationships and assessed these relationships at different points in time. In one of the most sophisticated examination to date, Norton and Kazantzis (2016) compared the relationship with the group leader to 
the relationship with other group members, and found that the patients' working alliance with the group leader and the cohesion among the group members both significantly predicted the next session's anxiety scores. However, the working alliance with the group leader was consistently associated with subsequent symptoms across all of the treatment sessions, while the cohesion among the group members was only significantly related to subsequent symptoms in later group sessions. This finding suggests that the impact of a patient's relationship with the group leader precedes the positive impact of relationships with the other group members.

Research is emerging using actor-partner interdependence modeling that indicates a mutual influence of the individual on the rest of the group and vice versa (Kivlighan, 2011; Lo Coco, Gullo, Di Fratello, Giordano, \& Kivlighan, 2016), including the association between a patient and other group members' perceptions of alliance (Tasca et al., 2010). For example, Gullo and colleagues (2014) found that other group members' aggregated perceptions of the alliance to the group as a whole had a positive influence on the subsequent alliance ratings of individual patients, suggesting that group members tend to develop a common conception of alliance to the group across sessions, especially in the good outcome cases. One of the most comprehensive studies by Bakali, Wilberg, Hagtvet, and Lorentzen (2010) examined patients, leaders, and groups as sources of variation accounting for patient rated alliance (and cohesion) at three stages of group psychotherapy. The researchers found that variability across groups accounted for more of the patientleader alliance early in group therapy, whereas variability across therapists became a more important predictor of the patient-leader alliance later in group therapy. These findings supported the notion that the group represented the strongest source of variation in the member-leader alliance, especially early in group treatment.

Overall, there is consistent evidence of the positive association between group alliance and patient outcomes across a range of psychiatric conditions (e.g., Crowe \& Grenyer, 2008; Joyce, Piper, \& Ogrodniczuk, 2007; Tasca, Balfour, Ritchie, \& Bissada, 2007; Thompson-Hollands et al., 2018). However, the impact of group alliance in predicting subsequent outcome is still debated, as it was in individual treatments (Falkenström, Ekeblad, \& Holmqvist, 2016; Rubel, Rosenbaum, \& Lutz, 2017; Zilcha-Mano et al., 2016). Is it the alliance that causes subsequent symptom change or is it early symptom change that improves the therapeutic alliance? Some recent findings support the view that increasing alliance is a precondition for symptom reduction in group treatments. For example, Tasca, Compare, Zarbo and Brugnera (2016) found that greater change in alliance was associated with subsequent lower levels of symptoms among patients who binge eat, whereas previous change in binge eating symptoms was not associated with subsequent al- liance levels. Moreover, similar to individual therapy (Kivlighan \& Shaughnessy, 2000) there is initial evidence that individual ratings of group alliance can be represented by a quadratic curve, with patients rating alliance to the therapist as lower during the middle sessions compared with the early sessions and later sessions (Maxwell et al., 2018).

As indicated, group research on alliance ruptures-repair patterns and their association with patient's outcome is scarce. To our knowledge, only one study has examined patterns of alliance ruptures in group treatment (Watson, Thomas \& Daffern, 2017) and none have examined the repaired-rupture event as a predictor of treatment outcome in group therapies. Watson and colleagues (2017) explored the ruptures in the therapeutic alliance between sexual offenders and their therapists in a structured group treatment program. Thirty participants $(55.6 \%)$ reported experiencing a rupture in the alliance; and half of them reported that the rupture was repaired. Moreover, offenders who perceived a non-repaired rupture reported lower scores on the Working Alliance Inventory (WAI; Hatcher \& Gillaspy, 2006). Tzur Bitan, Zilcha-Mano, Ganor, Biran, \& Bloch (2018) reported a case description to illustrate how group leaders can manage alliance ruptures in the context of support groups for parents of children with autistic spectrum disorder. These findings are preliminary and further investigation with larger samples and different clinical populations are warranted. Moreover, studies on alliance rupture-repair in group treatment should address the structural complexity of the group format with more sophisticated research strategies to disaggregate individual and group variability in alliance and outcome.

\section{The dyadic nature of therapeutic alliance and its multi-person dimensions in group settings}

Theorists and researchers argue that patients' and therapists' common view on the therapeutic relationship and alliance is an important element of a successful treatment given the interpersonal nature of the alliance construct (Marmarosh \& Kivlighan, 2012). However, meta-analytic results found a small or moderate level of congruence in ratings of alliance between therapists and patients, with therapists on average rating the alliance lower than their patients (with a standardized mean difference of $\mathrm{d}=0.63$; Tryon, Blackwell, \& Hammel, 2007). Atzil-Slonim and colleagues (2015) argued that conflicting alliance perceptions in the therapeutic dyad (e.g., patient and therapist differing in their alliance ratings) can lead to a less effective therapy.

Research has suggested the importance of the assessment of congruence and discrepancy in levels of the alliance in the therapeutic dyad. Such studies used new methods for analyzing dyadic data, such as the truth and bias model and response surface analysis (Marmarosh \& 
Kivlighan, 2012; West \& Kenny, 2011). For example, Zilcha-Mano, Snyder, and Silberschatz (2016) showed that higher agreement between patients' and therapists' perceptions of a positive alliance predicted lower symptom levels. Furthermore, Rubel and colleagues (2018) found that dyads in which patients and therapists similarly perceived session-to-session changes in the therapeutic bond showed a greater reduction in patients' symptoms.

In group therapy, the structural complexity of interactions among group members, group-as-a-whole, and therapist require studies that use advance methodologies to disaggregate the variance associated with the three structural levels of the group. Only a few studies examined the impact of alliance agreement and disagreement on group outcome. The study by Lo Coco, Gullo, and Kivlighan (2012) used response surface analysis and showed that patient symptom reduction was greater when the individual group member and the other group members' perceptions of their alliance to the group as a whole were in agreement. A study by Compare, Tasca, Lo Coco, and Kivlighan (2016) analyzed the longitudinal scores of both patients' and therapists' working alliance and found that the group leaders did not distinguish among the group members in terms of the strength of their alliances. Thus, group leaders seem to have a biased perception of an individual group member's alliance based on the aggregate of the rest of the group's alliance scores. However, when the group leader rated the individual patient's alliance in a less biased manner (not influenced by the rest of the group's alliance), then that group member benefited the most from group therapy. Finally, Kivlighan, Lo Coco, Oieni, Gullo, Pazzagli, and Mazzeschi (2017) examined the consequences of congruence and discrepancy among the different positive bonding relationships in group therapy. These authors found that when positive bonding between the leader and group members were more discrepant, group members had worse outcome. Moreover, the discrepancy between positive bonding with the group members and the group-as-a-whole was also related to poorer outcome. Overall, these studies indicate the importance of analyzing congruencies and discrepancies in individual perceptions of alliance between a group member, the therapist, and the group as a whole, and can set the stage for an initial examination of the rupture-repair process in group treatment.

\section{Methodology for operationalizing alliance ruptures}

In this section we describe a research methodology for operationalizing alliance ruptures. We will use a group member's alliance with the leader as the example of alliance ruptures, but it is important to keep in mind that alliance ruptures can also occur between a member and another group member or between a member and the group-as-a-whole. Kivlighan et al. (2017) described how polynomial regression and response surface analysis (PRRSA) can be used methodology to operationalize intrapersonal ruptures, which arise when a group member sees discrepancies among structural aspects of the alliance. For example, a group member may have a strong alliance with the group leader but a weak alliance with the other group members. Here we will describe how PRRSA can be used to operational three other types of alliance ruptures that can occur in group therapy.

First, member (self) temporal inconsistency ruptures are similar to how alliance ruptures occur and are operationalized in individual therapy. For example, a group member's alliance to the group leader within a group therapy session may be significantly lower than the member's typical (average) alliance to the group leader across sessions. This significantly lower within-session alliance is a sign that a rupture has occurred in that session, in relation to one's self. Second, member-to-group temporal inconsistency are alliance ruptures unique to the group setting. For example, an individual group member's alliance to the group leader in a group session may be significantly lower than the group-as-a-whole's typical (average) alliance to the group leader. This significantly lower alliance is a sign that a rupture has occurred in that session for an individual relative to the group. Third, member-to-group interpersonal alliance ruptures arise when there is a discrepancy in the alliance between a member and the group. For example, a group member's typical (average) alliance to the group leader may be significantly lower than the group-as-a-whole's typical (average) alliance to the group leader. This significantly lower alliance is a sign that a rupture has occurred between the individual and the group. As described above, ruptures can be conceptualized as discrepancies. PRRSA offers a good way to operationalize discrepancies and therefore to examine the effects of different types alliance ruptures in groups based on the different structural relationships in groups.

To illustrate the use of PRRSA, we provide a brief example of the response surface examining the effects of member (self) temporal inconsistency ruptures. The PRRSA is conducted with a 3-level multi-level model: groups, members and sessions. To use PRRSA one first partitions longitudinal alliance-to-the-leader ratings into: i) between-group alliance to the leader (the average alliance to the leader across all group members); ii) withingroup alliance to the leader (a group's members' average alliance to the leader across all sessions); iii) within-member alliance to the leader (a deviation score in which a members alliance to the leader in a session is subtracted from that member's average alliance to the leader across all sessions). These i, ii, iii variables (and cross-level interactions) can be regressed on members' session outcome. The response surface in Figure 1 is a hypothetical, 3-dimesional representation of the effects of members' (self) temporal inconsistency ruptures and group mem- 
bers' session outcomes. In Figure 1, the x-axis reflects a member's average level of alliance to the group leader across all sessions, the y-axis reflects a member's level of alliance in a session, and the z-axis reflects the predicted level of group session outcome. Therefore, the response surface represents the predicted level of group member session outcome for a given combination of average alliance to the group leader and alliance to the group leader in a session.

The line of discrepancy is depicted on the $x-y$ plane in Figure 1. The shape of the response surface above the line discrepancy indicates how different combinations of average alliance to group leader and specific session alliance to the group leader are related to session outcome.

In examining the shape of the response surface above the line of discrepancy the response surface tilts upward, toward the right-hand side of the figure. A significant negative slope, shows that as members' alliance to the leader become increasingly lower than their average alliance to the leader, member's session outcome decreases. Therefore, greater negative discrepancy between session alliance to the leader and average alliance to the leader, an indication of a member (self) temporal inconsistency rupture, is related to poorer session outcome.

As previously mentioned, PRRSA was adopted in some studies to examine disagreements among group members on their rating of alliance (Kivlighan et al., 2017; Lo Coco et al., 2012) and this model seems to be a promising strategy to examine the alliance rupture-repairs in the group psychotherapy context. These studies seem also to depict a useful framework for analyzing group alliance rupture-repair process. What happens in group ther- apy when the patient and the group leader do not fit in their perceptions of the alliance to the group as a whole? How does this disagreement on alliance impact the patient's outcome? For example, in sessions where the therapist rates the alliance bond lower than a group member, it is likely that the therapist perceives a problem in the bond which is not recognized by the patient, suggesting a possible withdrawal rupture in which the patient denies a conflict or problem (Safran \& Muran, 2000). Furthermore, the agreement among group members on a high alliance might indicate a positive environment for therapeutic group work, whereas agreement on a low alliance might indicate the need for the group leader to specifically repair problems in the alliance to the group (Kivlighan et al., 2017; Lo Coco et al., 2012). PRRSA studies provide initial evidence that: when the group member's perceptions of the alliance are weaker than the other group members' alliance to the group as a whole, greater symptom reduction occurs (Lo Coco et al., 2012); and that when the discrepancy between positive bonding with the leader and other group members increases, the group member reports a worse outcome.

This research can also provide clinicians with important suggestions on how to manage the alliance ruptures. Group leaders are typically trained to pay attention to the strength of the relationships in the group (Yalom \& Leszcz, 2005). This research suggests that group leaders need also to pay attention to the congruence or incongruence among the structural aspects of the relationships. Some following clinical examples can help in understanding the complexity of the rupture-repair process in groups.

\section{Members' Session outcome}

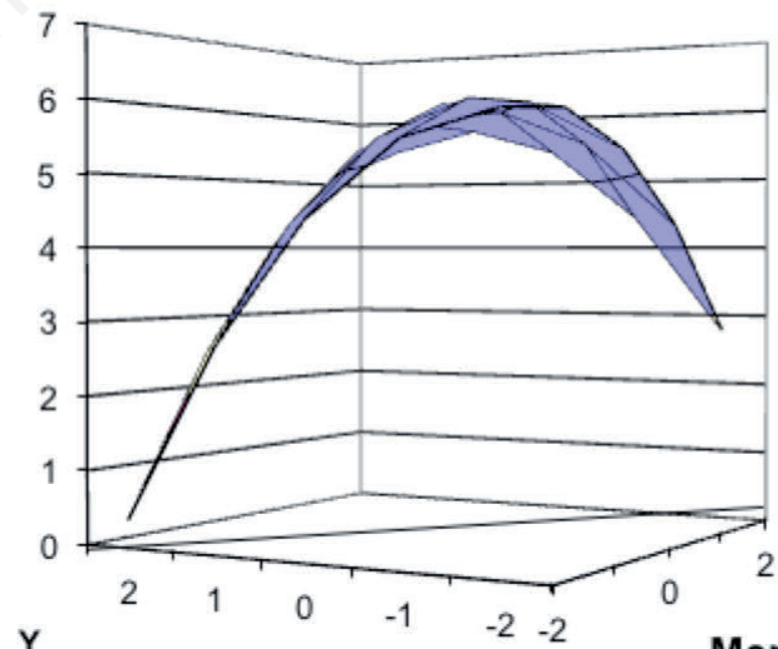

Members' Average (across all sessions) alliance to the Group Leader

Figure 1. The effects of members' (self) temporal inconsistency ruptures and group members' session outcomes. 


\section{Clinical examples of alliance ruptures and repair in group therapy}

Given the structural complexity of group interactions and the different levels involved in group dynamics (i.e., group members, therapist, group as a whole), the alliance ruptures and repairs are multifacted at each of these levels. To illustrate this complexity in clinical contexts, we provide these clinical vignettes to illustrate the multidimensional complexity of the rupture and repair process in group settings.

\section{Member to group withdrawal rupture without resolution}

First we will describe two therapeutic ruptures that take place in a time-limited, close-ended group comprised of seven members and two leaders. The first rupture exemplifies a withdrawal rupture between the group and one of its members, followed by the member terminating early from group. The second is an example of a confrontation rupture involving the group and the group leaders. These two ruptures follow from an event in the final third of a 12-session dynamic relational group treatment for perfectionism (Hewitt, Flett, \& Mikail, 2017). The first rupture takes place in Session 9 and the second rupture takes place in Session 11.

The event that seems to be at the heart of both ruptures took place at the beginning of Session 9 when group member Greta began by saying that the past week had been difficult for her because she came across several Facebook posts that referred to the death of her old college roommate. Greta stated that her focus on career and her relationship with her partner contributed to losing touch with this friend over the past few years but that, at one point, they had been quite close. Drew, another group member, was the first to respond, saying that he had never experienced that sort of loss but that he wanted to be sympathetic. Other members remained silent, at which point Greta moved away from her feelings by telling the group that she had handled things as well as she could by taking time off work and not worrying about what others thought. Drew affirmed her for taking care of herself and managing her pain in a different manner than she had in the past. After another short silence, several group members, in turn, began to share that they too had had a difficult week, with each going on to describe various challenges that unfolded since the group had last met. The seeming indifference to Greta's loss was striking, particularly in light of the group's fondness of her.

This withdrawal rupture on the part of the group as a whole seems to have started when the leaders failed to draw the group's attention to the lack of response to Greta's loss. Instead, the leaders focused on the process by which several group members, led by Drew, voiced frustration with the persistent silence and apparent lack of engagement in past sessions by another group member, Blaire. The emotional tone of the group shifted to one of anger and disapproval as Blaire became the scapegoat, with group members projecting onto him their own failure to be emotionally present to their own pain and Greta's pain. Near the end of the session Stewart, the male coleader, made an indirect attempt to invite members of the group to reflect on how silence in the face of one's vulnerability can be difficult, but may hold deeper meaning.

Stewart (co-leader): "It seems silence is difficult for the group. Yet, I'm also aware that earlier today Greta's solemn moment led Allan (another group member) to reflect on deeper feelings".

Drew (member): "I wonder if when we are being silent it allows us to connect with what is going on inside".

Jane (member): "Yes, the lack of overt response might just mean that we are thinking about something that is happening".

Stewart's intervention was an attempt to re-establish the emotional bond between members of the group and Greta by reframing the meaning of silence. He used metacommunication to reflect on the nature of the group's limited response to Greta earlier in the session. However, the intervention fell short of what was needed on several accounts. First, it came late in the session, so there was insufficient time to process the group's avoidance of grief and its connection to impending termination. Second, neither the group leaders nor group members circled back to Greta by making the connection between Drew's frustration with Blaire's silence and what Greta may have felt when there was a limited response to her loss. Finally, Josephine, the female co-leader, was uncharacteristically quiet for much of the session, leaving Stewart to process and manage the group's interactions largely on his own.

The therapists both responded in ways that were not consistent with their usual clinical styles thus far in the treatment. In her supervision Josephine (co-therapist) shared that during the session she felt annoyed that the group was not supportive of Greta and her distress. Josephine acknowledged that her annoyance led her to become quiet and passive for most of the session. In contrast, Stewart (co-therapist) became much more active and vocal than usual in facilitating and exploring the group's frustration with Blaire. In supervision, it became clear that for Stewart the process of his avoiding acknowledging and exploring the group's lack of support for Greta was not only distressing to the leaders but was discussed in terms of a reenactment of Greta's past relational dynamics in her family. Specifically, Greta had shared that as a child her mother often told she was loved and perfect just the way she is. Yet, Greta also noted that her mother was seldom emotionally available to her as her mother always seemed to be working or was otherwise preoccupied with various matters. The development of Greta's perfectionism (her need to be perfect) likely evolved from this past dynamic. Unfortunately, just prior to the beginning of the 
next sessions (i.e., session 10) Greta informed the therapists that this would be her final session. Unlike individual therapy, groups may continue even after an individual member stops attending. In this case, the group's withdrawal rupture with Greta, and her decision to leave the group before it ended (her own withdrawal rupture with the group) continued to reverberate within the group and contributed to a confrontation rupture in a later session as described below.

\section{Therapist to group confrontation rupture and resolution}

This second vignette is an example of a confrontation rupture that occurred between the group-as-a-whole and the leaders during session 11 . The session began with Drew announcing that during the previous week one of his cousins died of a drug overdose. Drew spoke for a few minutes about his cousin's troubled life and how members of his family had written-off his cousin years ago. Drew expressed feelings of both sadness and guilt, the latter stemming from having failed to reach out to his cousin sooner. Josephine, one of the group leaders, responded by saying to Drew how sorry she was to hear of his loss, and how hard it must be for him given the circumstances. Drew was clearly moved by Josephine's response, and went on to say that he was also feeling angry toward his family for having been so hard on his cousin over the years. Drew's comments were followed by a prolonged silence.

Josephine (leader): "I'm aware of the group's silence. I wonder what people are feeling".

Jane: "I want to create space for Drew's feelings".

Albert: "I need to understand the context of Drew's loss, emotionally".

Drew: "Well, when my mom first called me, and she sounded distraught, I immediately thought that something had happened to our new dog. So, when she told me it was my cousin, my first response was one of relief that the dog was okay. When the reality of what had happened sank in, I felt really badly about that. I had a complicated relationship with my cousin. I'd sometimes try to encourage him but then there would be an extended periods of time when we didn't see or talk to each other. I feel sad that I didn't see the extent of his struggle - I feel I've failed him".

(Extended silence, Drew looking down at the floor appearing quite sad).

Stewart (co-leader): To Drew, and more subtly, to the group as a whole. "It seems like you're reflecting on how ready you are to meet the needs of others and questioning whether what you do is enough".

The group's emotional paralysis seemed to be an expression of a more pervasive struggle with the themes of death and ending. Stewart's comment was aimed at both the exchange that had just unfolded with Drew, but was also an indirect comment on what had occurred in session nine with Greta's disclosure of the loss of her college roommate. At a deeper level, Stewart's intervention was an allusion to Greta's "death"/departure from the group that contained parallel elements to the relational dynamic between Drew and his cousin. Josephine's (co-leader) expression of sympathy in response to Drew's loss was intended to model empathic attunement and the importance of emotional presence in the face of another's pain and vulnerability.

The combined interventions made by the leaders (Josephine noting the silence and Stewart commenting about readiness to meeting the needs of others) unleashed a barrage of anger towards the leaders from the group - a confrontation rupture. One member stated that she felt criticized by Stewart's comment. Another took aim at Josephine's "wondering about the silence" by suggesting that the leaders seem to have a defined set of canned responses. Another member said that she is a quiet person and she wondered why silence seemed to be viewed negatively by the leaders.

We understood the exchange to be a product of discrepancy between the leaders and members with respect to both task and bond elements of the relationship. Members were struggling with how to achieve a balance between responding to needs of self and those of others. The sharing of significant losses through death and neglect of significant relationships underscored the impending termination and the loss of the bond that had been forged among group members. On several occasions over the course of sessions 10 through 12 group members returned to the topic of whether there was interest in maintaining contact once the group was over and how best to achieve that.

The leaders addressed the confrontation rupture by clarifying that their intention was not to be critical, but rather to invite an exploration of the theme of whether what members offered each other over the life of the group was enough.

Jane (group member): "I'm really trying to be less critical of myself".

Anthony (group member): "I have a hard time not being critical of myself. Recently, my sister pointed out that I often lean on her more than allowing her to lean on me, and that was really hard to hear".

Jane (group member): "I wondered how Drew interpreted my silence".

Albert (group member): "I needed to sit with Drew's announcement in order to feel what he is feeling".

Anthony (group member): "I learned that sometimes it's best to not say anything, but then I wonder how long I have to sit in the silence before I can say something".

Drew (group member): "Silence make sense for me because it took me time to get a sense of how I felt about what happened. There is also the shock value and the need to process such unexpected news".

Stewart (co-leader): "I'm really struck by how different this exchange is from where the group seemed to be 
at when Greta announced the death of her roommate".

The clarifying statement offered by Stewart, coupled with Josephine's tone of non-defensive acceptance regarding the group's confrontation served to soften the emotional tone reflected in the exchanges that followed. Several members of the group spoke openly about disappointments and regret that they had missed opportunities to gain more awareness of their blind spots. Others expressed a mix of excitement and anticipation in response to the final session because they knew that the co-leaders would be offering summary feedback, much as they had done when Greta left the group.

\section{Member to member withdrawal rupture and resolution}

In this next example we illustrate a member-to-member therapeutic alliance rupture that was subsequently repaired with the group therapist's intervention. This group, which is different from the one described above, had seven adult members who had different diagnoses, but who all wanted to work on relationship problems. The treatment was based on a group psychodynamic-interpersonal therapy model similar to what was described by Hewitt and colleagues (2017) and Tasca and colleagues (2006). The group had a rolling admission structure, so that as a member graduated or left the group, a new member was introduced.

In this session, Gail a newer member was attending her fifth session. She reported a high level of social anxiety, described often feeling dismissed by others, and feeling that she "can never can do anything right" in relationships. Robbie, a member who was in the group for a number of months, reported feeling lonely and isolated in his life, his intentions were often misunderstood by others, and he resorted to intellectualizing when feeling anxious and sad. He was the group's historian, often remembering and summarizing what occurred in previous sessions. During this session, Gail, for the first time began speaking tentatively about her anxiety in social situations, and her difficult childhood. She spoke briefly and in not much detail, but she was clearly anxious and became tearful at one point. The therapist asked her how she felt about having disclosed this information to the group, and Gail responded that it was difficult but that it was "ok". Some other group members provided some validation of her attempts to disclose for the first time in the group. This meeting also was the first session for Neil who was relatively quiet. At the end of the session, the therapist asked the group to describe to Neil if this was a typical session as a means of helping Neil to know what to expect from the group experience. Robbie, in his role of historian, said that this group session was typical, though he felt the meeting was more superficial and not as emotional as most sessions. Gail, looked visibly surprised and her face reddened. The therapist realized that a therapeutic rupture had oc- curred, as Robbie appeared to dismiss Gail's attempts to engage. However, the session was at an end, so the therapist suggested that they return to what occurred during the next week's session. At most sessions, the therapist let the group start, but at the next session, the therapist started the meeting.

Therapist: "I wanted to return to what happened last week with you, Gail and Robbie".

Gail (feigning surprise): "Oh, what happened?" (indicating a withdrawal rupture).

Therapist: "You seemed upset at what Robbie said at the end".

Gail (tearing up): "Oh, yah (pause). I felt like 'here we go again, I'm not good enough'."

Robbie: "You know it's normal for people to feel that way at the beginning. And I was just describing what happened to Neil".

Therapist: "Gail, how did you feel about what Robbie said last week?"

Gail: (tearful). "I feel that he did not appreciate how difficult it was for me to talk. But you know it shouldn't be so difficult - I should know better".

Therapist: "I know you might want to criticize yourself, but let's stick with what happened for now. (Turning to the group) How did the group see what happened at the end of last week".

Renee (group member): "I think Robbie didn't realize that he was not being sensitive to Gail (others in the group nodding). Robbie, I think that happens sometimes in the group - you are good at describing things but sometimes you aren't aware of how others might take it".

Robbie: “Ok. Ok. I see that - I've gotten that feedback before. I'm sorry, Gail - I guess I should have realized that that was hard for you".

Gail: "No, it's my fault".

Robbie: "No, you have a right to talk about yourself at your own pace. And I need to be more sensitive to that".

Gail: "Ok".

The key therapist role here was to identify that a rupture had occurred, and to bring it back to the group for reparation at the next opportunity, and not allowing Gail to withdraw by claiming she did not remember or register what happened at the end of the last session. The withdrawal rupture might have been evident in discrepant alliance ratings. Gail might have rated the alliance to Robbie as high, whereas the therapist's or even the group's rating of her alliance to Robbie might have been low. The therapist encouraged the group to help with the repair to the bond between Gail and Robbie, and the group members provided a supportive context to make that occur. Gail was able to see that Robbie's dismissing of her was partly due to his own limitations in understanding others' needs and intentions, and not due primarily to her own faults. Robbie, for his part owned his error which was key to the resolution. 


\section{Conclusions}

Research and clinical writing on therapeutic alliance ruptures and repairs represent an important advance in therapeutic alliance theory and practice. The dynamic development of the alliance over time, its fluctuations, and its impact on outcomes are well described by the concepts of withdrawal and confrontation ruptures and therapists' attempts to repair these. Zilcha-Mano (2017) argued that the alliance is curative in and of itself and that potentially the curative aspects of psychotherapy rests with the resolution of alliance ruptures especially for individuals with more trait-like interpersonal problems. That is, the process of repair likely restores a sense of trust in others and strengthens the therapeutic bond. Similarly, Yalom and Leszcz (2005) argued that the group represents a recapitulation of early family experiences, and therefore conflicts and resolutions in groups inherently provide a transformative emotional experience.

The research and practice related to alliance ruptures and repairs in individual psychotherapy has made important strides in the past decades. The research has benefitted from advances in statistical methodologies that allow one now to disaggregate within and between individual variability in the alliance-outcome relationship including the use of longitudinal statistical time-lagged models. This research provides a clearer view of the importance of the alliance, the key role of alliance ruptures, and to the clinical utility of repairing ruptures (EubanksCarter et al., 2012; Falkenstrom et al., 2013; ZilchaMano, 2017).

Despite the advances in individual psychotherapy research and practice, group therapy writings on alliance ruptures and repairs has not kept pace. Part of the challenge is that group therapy represents a complex set of interactions between the group member to therapist, member to member, and member to group (Burlingame et al., 2013). When considering the alliance in group therapy, one must think multidimensionally and this has created challenges for both group clinicians and group researchers. And yet there are notable advances in the research. For example, in a several papers, Kivlighan and colleagues (e.g., Compare et al., 2016; Kivlighan, Lo Coco, Gullo, Pazzagli, \& Mazzeschi, 2017; Marmarosh \& Kivlighan, 2012) applied advanced statistical models (the truth and bias model, actor-partner interdependence modeling, response surface analysis) to look at the interactions that occur at multiple levels of group functioning at the same time. These studies have advanced the field by focusing on congruence and discrepancies in alliance between members and therapists and between members and the group. We suggest here that discrepancies in alliance ratings at various levels of the group may be indicators of alliance ruptures and PRRSA is a promising strategy to examine group member's alliance in the context of the alliances of the other group members. How- ever, the research in groups needs to go further and begin to adapt and apply alliance rupture ratings, such as with the 3RS (Eubanks et al., 2015) or the Collaborative Interactions Scale (Colli et al., 2017) to begin to untangle the relative impacts of alliance ruptures and to give therapists direction on how to best repair different types of alliance rupture at different levels in the group. To illustrate some of these challenges and concepts, we provided three clinical vignettes of alliance ruptures and repairs or failures to repair. The vignettes show the importance of therapists' abilities to identify alliance ruptures, to see how the ruptures have a ripple affect across members of the group and across sessions, how repairing a rupture can increase cohesion and trust in a group, and how failure to repair a rupture may lead to poorer processes and outcomes. We, and countless colleagues who strive to gain a deeper understanding of the the complex interplay between clients, groups, and therapists owe a debt of gratitude to Jeremy Safran for his pioneering work on the therapeutic alliance (Eubanks-Carter, Muran, \& Safran, 2010; Muran et al., 2009; Safran \& Kraus, 2014; Safran \& Muran, 2000; Safran et al., 2011). Our paper illustrates the enduring legacy of this work and its potential application to the group therapy context. Clinical practice in group therapy will be enriched in the coming years as the processes and interventions related to group therapeutic alliance ruptures and repairs become more deeply understood by the research into this complex phenomenon.

\section{References}

Atzil-Slonim, D., Bar-Kalifa, E., Rafaeli, E., Lutz, W., Rubel, J., Schiefele, A.-K., \& Peri, T. (2015). Therapeutic bond judgments: Congruence and incongruence. Journal of Consulting and Clinical Psychology, 83(4), 773-784. doi: 10.1037/ccp0000015

Bakali, J. V., Baldwin, S. A., \& Lorentzen, S. (2009). Modeling group process constructs at three stages in group psychotherapy. Psychotherapy Research, 19, 332-343. doi: 10.1080/10503300902894430

Bakali, J. V., Wilberg, T., Hagtvet, K. A., \& Lorentzen, S. (2010). Sources accounting for alliance and cohesion at three stages in group psychotherapy: Variance component analyses. Group Dynamics: Theory, Research, and Practice, 14(4), 368-383. doi: 10.1037/a0019170

Beck, A. P., \& Lewis, C. M. (2000). The process of group psychotherapy: Systems for analyzing change. Washington: American Psychological Association.

Bordin, E. S. (1994). Theory and research on the therapeutic working alliance: New directions. In A. O. Horvath \& L. S. Greenberg (Eds.), The Working alliance: Theory, research, and practice (pp. 13-37). New York, NY: Wiley.

Burlingame, G. M., Fuhriman, A., \& Johnson, J. E. (2002). Cohesion in group psychotherapy. In J. C. Norcross (Ed.), Psychotherapy relationships that work (pp. 71-87). New York: Oxford University Press.

Burlingame, G. M., MacKenzie, K. R., \& Strauss, B. (2004). Small-Group Treatment: Evidence for Effectiveness and Mechanisms of Change. In M. J. Lambert (Ed.), Bergin and 
Garfield's Handbook of Psychotherapy and Behaviour Change ( $5^{\text {th }}$ ed., pp. 647-696). New York: Wiley.

Burlingame, G. M., Strauss, B., \& Joyce, A. (2013). Change mechanisms and effectiveness of small group treatments. In M. J. Lambert (Ed.), Bergin \& Garfield's Handbook of Psychotherapy and Behavior Change (6th ed., pp. 640-689). New York: Wiley.

Burlingame, G. M., McClendon, D. T., \& Yang, C. (2018). Cohesion in Group Therapy: A Meta-Analysis. Psychotherapy, 55, 384-398. doi: 10.1037/pst0000173

Colli, A., Gentile, D., Condino, V., \& Lingiardi, V. (2017). Assessing alliance ruptures and resolutions: Reliability and validity of the Collaborative Interactions Scale - revised version. Psychotherapy Research, 22, 1-14. doi: 10.1080/10503307.2017.1414331

Compare, A., Tasca, G. A., Lo Coco, G. Kivlighan, D. M. (2016). Congruence of group therapist and group member alliance judgments in emotionally focused group therapy for binge eating disorder. Psychotherapy, 53(2), 163-173. doi: $10.1037 /$ pst0000042

Crits-Christoph, P., Gibbons, M. B. C., \& Mukherjee, D. (2013). Psychotherapy process-outcome research. In M. J. Lambert (Ed.), Bergin and Garfield's handbook of psychotherapy and behavior change (pp. 298-340). New York: Wiley.

Crowe, T. P., \& Grenyer, B. F. S. (2008). Is therapist alliance or whole group cohesion more influential in group psychotherapy outcomes? Clinical Psychology \& Psychotherapy, 15, 239-246. doi: 10.1002/cpp.583

Doran, J. M. (2016). The working alliance: Where have we been, where are we going? Psychotherapy Research, 26(2), 146163. doi: 10.1080/10503307.2014.954153

Doran, J. M., Safran, J. D., Waizmann, V., Bolger, K., \& Muran, J. C. (2012). The alliance negotiation scale: psychometric construction and preliminary reliability and validity analysis. Psychotherapy Research, 22, 710-719. doi: 10.1080/ 10503307.2012.709326.

Eubanks, C. F., Muran, J. C., \& Safran, J. D. (2015). Rupture Resolution Rating System (3RS): Manual. Unpublished manuscript, Mount Sinai- Beth Israel Medical Center, New York.

Eubanks, C. F., Muran, J. C., \& Safran, J. D. (2018). Alliance Rupture Repair: A Meta-Analysis. Psychotherapy, 55, 508519. doi: 10.1037/pst0000185

Eubanks-Carter, C., Muran, J. C., \& Safran, J. D. (2010). Alliance ruptures and resolution. In J. C. Muran \& J. P. Barber (Eds.), The therapeutic alliance: An evidence-based approach to practice and training (pp. 74-94). New York, NY: Guilford Press.

Eubanks-Carter, C., Gorman, B. S., \& Muran, J. C. (2012). Quantitative naturalistic methods for detecting change points in psychotherapy research: An illustration with alliance ruptures. Psychotherapy Research, 22, 621-637. doi:10.1080/ 10503307.2012.693772

Falkenström, F., Granström, F., \& Holmqvist, R. (2013). Therapeutic alliance predicts symptomatic improvement session by session. Journal of Counseling Psychology, 60(3), 317328. doi: 10.1037/a0032258.

Falkenström, F., Ekeblad, A., \& Holmqvist, R. (2016). Improvement of the working alliance in one treatment session predicts improvement of depressive symptoms by the next session. Journal of Consulting and Clinical Psychology, 84, 738-751. doi: 10.1037/ccp0000119

Flückiger, C., Del Re, A. C., Wampold, B. E., \& Horvath, A. O.
(2018). The Alliance in Adult Psychotherapy: A Meta-Analytic Synthesis. Psychotherapy, 55(4), 316-340. doi: 10.1037/pst0000172

Gullo, S., Lo Coco, G., Pazzagli, C., Piana, N., De Feo, P., Mazzeschi, C., \& Kivlighan, D. M. (2014). A time-lagged, actor-partner interdependence analysis of alliance to the group as a whole and group member outcome in overweight and obesity treatment groups. Journal of Counseling Psychology, 61, 306-313. doi: 10.1037/a0036084.

Gullo, S., Lo Coco, G., Di Fratello, C., Giannone, F., Mannino, G., \& Burlingame, G. (2015). Group climate, cohesion and curative climate. A study on the common factors in group process and their relation with members attachment dimensions. Research in Psychotherapy: Psychopathology, Process and Outcome, 18(1), 10-20. doi: 10.4081/ripppo. 2015.160

Hatcher, R. L., \& Barends, A. W. (1996). Patients' view of the alliance of psychotherapy: Exploratory factor analysis of three alliance measures. Journal of Consulting and Clinical Psychology, 64, 1326-1336. doi: 10.1037/0022-006X.64.6.1326

Hatcher, R. L., \& Gillaspy, J. A. (2006) Development and validation of a revised short version of the working alliance inventory. Psychotherapy Research, 16, 12-25, doi: 10.1080/10503300500352500

Hewitt, P. L., Flett, G. L., Mikail, S. F. (2017). Perfectionism. A relational approach to conceptualization, assessment, and treatment. New York: The Guilford Press.

Holmes, S. E., \& Kivlighan, D. M. (2000). Comparison of therapeutic factors in group and individual treatment processes. Journal of Counseling Psychology, 47, 478-484. doi: 10.1037/ 0022-0167.47.4.478

Horvath, A. O., \& Bedi, R. (2002). The alliance. In J. C. Norcross (Ed.), Psychotherapy relationships that work: Therapist contributions and responsiveness to patients (pp. 37-70). New York, NY: Oxford University Press.

Horvath, A. O., Del Re, A. C., Flückiger, C., \& Symonds, D. (2011). Alliance in individual psychotherapy. Psychotherapy, 48, 9-16. doi: 10.1037/a0022186

Jensen, J., \& Burlingame, G. M. (2018). An item reduction analysis of the group questionnaire. Psychotherapy, 55, 144150. doi: $10.1037 /$ pst0000145

Johnson, J. E., Burlingame, G. M., Olsen, J. A., Davies, D. R., \& Gleave, R. L. (2005). Group climate, cohesion, alliance, and empathy in group psychotherapy: Multilevel structural equation models. Journal of Counseling Psychology, 52, 310-321. doi: 10.1037/0022-0167 .52.3.310

Joyce, A. S., Piper, W. E., \& Ogrodniczuk, J. S. (2007). Therapeutic alliance and cohesion variables as predictors of outcome in short-term group psychotherapy. International Journal of Group Psychotherapy, 57, 269-296. doi: 10.1521/ijgp.2007.57 .3.269.

Kirchmann, H., Mestel, R., Schreiber-Willnow, K., Mattke, D., Seidler, K., Daudert, E., ... Strauss, B. (2009). Associations among attachment characteristics, patients' assessment of therapeutic factors, and treatment outcome following inpatient psychodynamic group psychotherapy. Psychotherapy Research, 19 (2), 234-248. doi: 10.1080/10503300902798367

Kivlighan, D. M., Lo Coco, G. \& Gullo, S. (2015). Is there a group effect? It depends on how you ask the question: intraclass correlations for California Psychotherapy Alliance Scale-Group items. Journal of Counseling Psychology, 62, 73-78. doi: 10.1037/cou0000046.

Kivlighan, D., Lo Coco, G., Gullo, S., Pazzagli, C., \& Mazzeschi, 
C. (2017). Attachment anxiety and attachment avoidance: Member attachment fit with their group and group relationships. International Journal of Group Psychotherapy, 67, 223-239. doi: 10.1080/ 00207284.2016.1260464

Kivlighan, D., Lo Coco, G., Oieni, V., Gullo, S., Pazzagli, C., \& Mazzeschi, C. (2017). All Bonds Are Not the Same: A Response Surface Analysis of the Perceptions of Positive Bonding Relationships in Therapy Groups. Group Dynamics: Theory, Research, and Practice, 21, 159-177. doi: $10.1037 / \mathrm{gdn} 0000071$

Kivlighan, D. M., \& Shaughnessy, P. (2000). Patterns of working alliance development: A typology of client's working alliance ratings. Journal of Consulting and Clinical Psychology, 47, 362-371. doi: 10.1037/0022-0167.47.3.362

Kivlighan Jr, D. M. (2011). Individual and group perceptions of therapeutic factors and session evaluation: An actor-partner interdependence analysis. Group Dynamics: Theory, Research, and Practice, 15(2), 147-160. doi: 10.1037/a0022397

Larsson, M. H., Falkenström, F., Andersson, G. \& Holmqvist, R. (2018). Alliance ruptures and repairs in psychotherapy in primary care. Psychotherapy Research, 28(1), 123-136. doi: 10.1080/10503307.2016.1174345

Lo Coco, G., Gullo, S., \& Kivlighan, D. M. (2012). Examining patients' and other group members' agreement about their alliance to the group as a whole and changes in patient symptoms using re- sponse surface analysis. Journal of Counseling Psychology, 59, 197-207. doi: 10.1037/ a0027560

Lo Coco, G., Gullo, S., Oieni, V., Giannone, F., Di Blasi, M., \& Kivlighan, D. M. Jr. (2016). The relationship between attachment dimensions and perceptions of group relationships over time: an actor-partner interdependence analysis. Group Dynamics: Theory, Research, and Practice, 20(4), 276-293. doi: $10.1037 / \mathrm{gdn} 0000056$

Lo Coco, G., Gullo, S., Di Fratello, C. Giordano, C. \& Kivlighan, D. M. Jr. (2016). Group Relationships in Early and Late Sessions and Improvement in Interpersonal Problems. Journal of Counseling Psychology, 63(4), pp. 419-428. doi: 10.1037/cou0000153

Marmarosh, C. L., \& Kivlighan, D. M. Jr. (2012). Relationships among client and counselor agreement about the working alliance, session evaluations, and change in client symptoms using response surface analysis. Journal of Counseling Psychology, 59, 352-367. doi: 10.1037/a0028907

Marmarosh, C. L., \& Tasca, G. A. (2013). Adult attachment anxiety: using group therapy to promote change. Journal of Clinical Psychology: In Session, 69(11), 1172-1182. doi: 10.1002/jclp.22044

Marmarosh, C., Markin, R., \& Spiegel, E. (2013). Attachment in group psychotherapy. Washington, DC: The American Psychological Association.

Marogna C., Caccamo F. (2014) Analysis of the process in brief psychotherapy group: the role of therapeutic factors. Research in Psychotherapy, Psychopathology, Process and Outcome, 17, 43-51. doi: 10.4081/ripppo.2014.161

Martin, D. J., Garske, J. P., \& Davis, M. K. (2000). Relation of the therapeutic alliance with outcome and other variables: A meta-analytic review. Journal of Consulting and Clinical Psychology, 68, 438-450. doi: 10.1037/0022-006X.68.3.438

Marziali, E., Munroe-Blum, H., \& McCleary, L. (1997). The contribution of group cohesion and group alliance to the outcome of group psychotherapy. International Journal of Group Psychotherapy, 47, 475-497. doi: 10.1080/ 00207284.1997.11490846
Maxwell, H., Compare, A., Brugnera, A., Zarbo, C., Rabboni, M., Dalle Grave, R., \& Tasca, G. A. (2018). Reflective functioning and growth in therapeutic alliance during emotionally focused group therapy for binge-eating disorder. Group Dynamics: Theory, Research, and Practice, 22(1), 32-44. doi: $10.1037 / \mathrm{gdn} 0000078$

Muran, J. C., Safran, J. D., Gorman, B. S., Samstag, L. W., Eubanks-Carter, C., \& Winston, A. (2009). The relationship of early alliance ruptures and their resolution to process and outcome in three time-limited psychotherapies for personality disorders. Psychotherapy: Theory, Research, Practice, Training, 46(2), 233-248. doi: 10.1037/a0016085

Norcross, J. C., Lambert, M. J. (2018). Psychotherapy relationships that work III. Psychotherapy, 55(4), 303-315. doi: $10.1037 /$ pst0000193

Norton, P. J., \& Kazantzis, N. (2016). Dynamic relationships of therapist alliance and group cohesion in transdiagnostic group CBT for anxiety disorders. Journal of Consulting and Clinical Psychology, 84, 146-155. doi: 10.1037/ccp0000062

Owen, J., Antle, B., \& Barbee, A. (2013). Alliance and group cohesion in relationship education. Family Process, 52, $465-$ 476. doi: 10 .1111/famp.12039

Rubel, J. A., Rosenbaum, D., \& Lutz, W. (2017). Patients' insession experiences and symptom change: Session-to-session effects on a within- and between-patient level. Behaviour Research and Therapy, 90, 58-66. doi: 10.1016/j.brat.2016.12.007

Rubel, J. A., Bar-Kalifa, E., Atzil-Slonim, D., Schmidt, S., \& Lutz, W. (2018). Congruence of Therapeutic Bond Perceptions and Its Relation to Treatment Outcome: Within- and Between- Dyad Effects. Journal of Consulting and Clinical Psychology, 86(4), 341-353. doi: 10.1037/ccp0000280

Safran, J. D., \& Muran, J. C. (2000). Negotiating the therapeutic alliance: A relational treatment guide. New York, NY: Guilford Press.

Safran, J. D., Muran, J. C., \& Eubanks-Carter, C. (2011). Repairing alliance ruptures. Psychotherapy, 48, 80-87. doi: $10.1037 /$ a 0022140

Safran, J. D., \& Kraus, J. (2014). Alliance ruptures, impasses, and enactments: A relational perspective. Psychotherapy, 51(3), 381-387. doi: 10.1037/a0036815

Strunk, D. R., Brotman, M. A., \& DeRubeis, R. J. (2010). The process of change in cognitive therapy for depression: Predictors of early inter-session symptom gains. Behaviour Research and Therapy, 48(7), 599-606. doi: 10.1016/j.brat.2010.03.011.

Tasca, G. A., Ritchie, K., Conrad, G., Balfour, L., Gayton, J., Daigle, V., \& Bissada, H. (2006). Attachment scales predict outcome in a randomized controlled trial of two group therapies for binge eating disorder: An aptitude by treatment interaction. Psychotherapy Research, 16, 106-121. doi: 10.1080/10503300500090928

Tasca, G. A., Balfour, L., Ritchie, K., \& Bissada, H. (2007). The relationship between attachment scales and group therapy alliance growth differs by treatment type for women with binge-eating disorder. Group Dynamics: Theory, Research, and Practice, 11, 1-14. doi: 10.1037/1089-2699.11.1.1

Tasca, G. A., Ramsay, T., Corace, K., Illing, V., Bone, M., Bissada, H., \& Balfour, L. (2010). Modeling longitudinal data from a rolling therapy group program with membership turnover: Does group culture affect individual alliance? Group Dynamics: Theory, Research, and Practice, 14, 151162. doi: $10.1037 / \mathrm{a} 0018778$ 
Tasca, G. A., \& Lampard, A. M. (2012). Reciprocal influence of alliance to the group and outcome in day treatment for eating disorders. Journal of Counseling Psychology, 59, 507-517. doi: $10.1037 /$ a0029947

Tasca, G. A., Francis, K. \& Balfour, L. (2014). Group Psychotherapy Levels of Interventions: A Clinical Process Commentary. Psychotherapy, 51(1), 25-29. doi: 10.1037/a0032520

Tasca, G. A., Compare, A., Zarbo, C., \& Brugnera, A. (2016). Therapeutic alliance and binge-eating outcomes in a group therapy context. Journal of Counseling Psychology, 63, 443-451. doi: 10.1037/cou0000159

Thompson-Hollands, J., Litwack, S. D., Ryabchenko, K. A., Niles, B. L., Beck, J. G., Unger, W., \& Sloan, D. M. (2018). Alliance across group treatment for veterans with posttraumatic stress disorder: The role of interpersonal trauma and treatment type. Group Dynamics: Theory, Research, and Practice, 22(1), 1-15. doi: 10.1037/gdn0000077

Tryon, G. S., Blackwell, S. C., \& Hammel, E. F. (2007). A metaanalytic examination of client-therapist perspectives of the working alliance. Psychotherapy Research, 17, 629-642. doi: 10.1080/10503300701320611

Tzur Bitan, D., Zilcha-Mano, S., Ganor, O., Biran, L., \& Bloch, Y. (2018). Routine measurement and feedback in support groups for parents of children with autistic spectrum disorder.
Psychotherapy, 55(2), 191-195. doi: 10.1037/pst0000140

Zilcha-Mano, S. (2017). Is the alliance really therapeutic? Revisiting this question in light of recent methodological advances. American Psychologist, 72(4), 311-325. doi: 10.1037/a0040435.

Zilcha-Mano, S., Snyder, J., \& Silberschatz, G. (2016). The effect of congruence in patient and therapist alliance on patient's symptomatic levels. Psychotherapy Research, 27, 371-380.

Zilcha-Mano, S., Muran, J. C., Hungr, C., Eubanks, C. F., Safran, J. D., \& Winston, A. (2016). The relationship between alliance and outcome: Analysis of a two-person perspective on alliance and session outcome. Journal of Consulting and Clinical Psychology, 84, 484-496. doi: 10.1037/ccp0000058

Watson, R., Thomas, S., \& Daffern, M. (2017). The Impact of Interpersonal Style on Ruptures and Repairs in the Therapeutic Alliance Between Offenders and Therapists in Sex Offender Treatment. Sexual Abuse, 29(7), 709-728. doi: $10.1177 / 1079063215617514$

West, T. V., \& Kenny, D. A. (2011). The truth and bias model of judgment. Psychological Review, 118, 357-378. doi: 10.1037/a002 2936

Yalom, I. D., \& Leszcz, M. (2005). The theory and practice of group psychotherapy (5th ed.). New York: Basic Books. 